\title{
Pugilismo e humor na imprensa italiana em São Paulo: representações no periódico II Pasquino Coloniale (1915-1939)
}

\section{Boxing and humor in the Italian press in São Paulo: representations in the II Pasquino}

Coloniale newspaper (1915-1939)

Boxeo y humor en la prensa italiana en São Paulo: representaciones en el periódico II Pasquino Coloniale (1915-1939)

Igor Cavalcante Doi ${ }^{\mathrm{a}}$ (D), Edivaldo Góis Junior ${ }^{\mathrm{a}}$ (D)

Palavras-chave

Boxe;

História do Esporte;

Imprensa;

Imigrantes Italianos.

Keywords

Boxing;

History of Sport;

Press;

Italian Immigrants.

Palabras clave

Boxeo;

Historia del Deporte;

Prensa;

Inmigrantes Italianos.

\begin{abstract}
RESUMO
Esta pesquisa teve por objetivo evocar as representações da prática pugilística produzidas pelo jornal ítalo-paulista II Pasquino Coloniale entre os anos 1915 e 1939, como parte de um estudo sobre esportes entre grupos imigrantes. Os resultados mostraram que o boxe era representado de modos diversos, por vezes com críticas à sua violência e ao dinheiro envolvido, mas também com paixão e empolgação. Como semanal humorístico, o Pasquino também troçava a identidade "científica" do boxe moderno e, em ocasiões específicas, debatia ora o caráter natural de sua violência, ora a construção do boxeador pela experiência.
\end{abstract}

\begin{abstract}
This research aimed to evoke the representations of pugilistic practice produced by the ItalianBrazilian newspaper // Pasquino Coloniale between the years 1915 and 1939, as part of a study on sports among immigrant groups. The results showed that boxing was represented in different ways, sometimes with criticism of its violence and the money involved, but also with passion and excitement. As a humorous weekly newspaper, Pasquino also mocked the "scientific" identity of modern boxing and, on specific occasions, debated either the natural character of its violence, or the construction of the boxer through experience.
\end{abstract}

\section{RESUMEN}

Esta investigación tuvo como objetivo evocar las representaciones de la práctica pugilística producidas por el periódico italiano-brasileño I/ Pasquino Coloniale entre los años 1915 y 1939 , como parte de un estudio sobre deportes entre grupos de inmigrantes. Los resultados mostraron que el boxeo estaba representado de diferentes maneras, a veces con críticas por su violencia y el dinero involucrado, pero también con pasión y entusiasmo. Como un semanario humorístico, Pasquino también se burló de la identidad "científica" del boxeo moderno y, en ocasiones específicas, debatió sobre el carácter natural de su violencia o la construcción del boxeador a través de la experiencia.

aUniversidade Estadual de Campinas, Faculdade de Educação Física, Programa de Pós-graduação em Educação Física, Área de concentração Educação Física e Sociedade. Campinas, SP, Brasil. 


\section{INTRODUÇÃO}

No decorrer do século XIX, o prizefighting ganhava considerável adesão, no mesmo passo em que via-se alvo das tentativas de regulamentação que o transformariam em boxe, ${ }^{1}$ mas foi no início do século XX que os efeitos dos ringues no mundo esportivo, na economia, no jornalismo e no cotidiano das pessoas atingiu outro patamar. Parte do novo furor deveu-se às iniciativas de institucionalização ${ }^{2}$ e, principalmente, à transformação dos combates em investimentos bastante rentáveis, com destaque à ação do empresário conhecido como Tex Richard, quem alçara o pugilismo a um negócio milionário.

Em 2 de julho de 1921, quando da realização do enfrentamento entre Dempsey e Carpentier diante dos oitenta mil espectadores acomodados no amplo Boyle's Thirty Acres em Jersey City, EUA (Roberts, 1974), o sucesso do pugilismo, como esporte e como negócio, atingia uma popularidade tão elevada e territorialmente extensa que, no Brasil, o jornal carioca Correio da Manhã dedicou toda a sua primeira página ao evento na data em que este ocorrera e quase toda ela no dia seguinte (Correio da Manhã, 2 de julho de 1921, p. 1; Correio da Manhã, 3 de julho de 1921, p. 1).

É nesse cenário, de grande popularidade do boxe no início do século XX em todo o mundo, que procuramos compreender as representações desse esporte em uma imprensa imigrante cada vez mais envolvida na dinâmica cultural de uma cidade como São Paulo, que no início do século XX era uma das maiores cidades de imigração do mundo (Hall, 2004). Mediante o crescimento de uma ampla variedade de atividades econômicas, constituía-se um mercado consumidor diversificado que retratava uma "nova urbe", desejando-se moderna - e adotando também hábitos considerados modernos, dentre os quais os esportes (Góis et al., 2015).

A partir da imprensa desta cidade e de sua circulação entre os seus leitores, selecionamos como fonte o semanal ítalo-paulistano /I Pasquino Coloniale, um periódico humorístico de caráter burguês (Trento, 2013) que chegou a ter tiragens de 30.000 exemplares e a ser distribuído não só no interior de São Paulo, mas também em outras regiões brasileiras. Sua existência é resultado desse fluxo de imigrantes italianos para a cidade de São Paulo, existente desde fins do século XIX, que produziu um público letrado urbano capaz de criar e consumir a imprensa étnica. Composta por operários, mas também por burgueses e profissionais liberais, a vida urbana dos

1 Tem-se por marco na formalização da prática a regulamentação proposta pelo Marquês de Queensberry em 1865, embora tenha havido outras tentativas de regramento do prizefighting desde o século anterior. Ver a revisão de Caratti (2017).

2 Um pouco sobre a institucionalização do Boxe pode ser visto em Loudcher e Day (2013). colonos favoreceu várias formas de empreendimentos que proporcionavam a reafirmação de suas identidades (Truzzi, 2016). A imprensa, nesse caso, tinha um papel fundamental de conectar a italianidade através da palavra escrita e das notícias de interesse particular da colônia, contribuindo para reafirmar uma identidade italiana fora do território nacional (Araújo e Cardoso, 1987; Roghatto, 1990).

É difícil estabelecer para o Pasquino uma linha editorial precisa, uma vez que sua diretoria foi ocupada por doze pessoas ao longo dos seus trinta e dois anos de existência. Ele foi fundado por Arturo Trippa em 1909 e pertenceu à Piccolo S/A, foi vendido e depois recuperado pela mesma sociedade, para ao final ser apropriado por Gaetano Cristaldi, de modo aparentemente independente. ${ }^{3}$ Sua tiragem, assim como sua longa permanência (o último número do qual temos notícia é de 1941), nos dá uma evidência de sua importância na imprensa em língua italiana no Brasil, onde, às margens do Fanfulla, ${ }^{4}$ poucos cabeçalhos conseguiam resistir à efemeridade.

O Pasquino se aproximava do estilo que marcava muitos periódicos brasileiros nas primeiras décadas do século XX, qual seja o de uma imprensa que buscava no humor chaves importantes para a escrita do dia a dia. $\mathrm{Na}$ avaliação de André (2010) a vida cotidiana no país estava distante dos ideais modernizadores e, assim, a representação das práticas pela reiteração do cômico vislumbrava as ambiguidades, as contradições e os paradoxos da vida em uma cidade brasileira que almejava uma modernidade não alcançada. Estas condições favoreceram, segundo o autor, a entrada de estrangeiros no campo da imprensa, sendo que o humor constituiu um elo entre a vida brasileira e os escritos dos jornalistas estrangeiros recém-chegados ao Brasil. Foi, assim, pelo humor que ali se produziram por e para imigrantes italianos representações sobre práticas cotidianas, revelando olhares particulares sobre as mudanças em curso naquele período, também vislumbradas no esporte.

A série documental foi recuperada a partir da Hemeroteca Digital da Biblioteca Nacional, onde nos foi possível acessar números de 1915 a 1939, com exceção dos anos 1923 e 1924. Pesquisando pelos termos box, boxe, pugilismo e pugilato, juntamos 312 recortes do

3 Essas informações foram obtidas através de uma investigação na imprensa sobre seus diretores.

${ }^{4}$ O Fanfulla foi o maior jornal da colônia italiana no Brasil e uma publicação relevante na história do periodismo brasileiro. Foi fundado em 1893 pelo ex-anarquista Vitaliano Rotellini e passou a emitir números diários em 1894, adquirindo abrangência nacional e importância capital na colônia alguns anos mais tarde. Como periódico burguês, arrecadava importâncias através de anúncios comerciais. No período compreendido por esta pesquisa, estava alinhado ao regime fascista peninsular (Malatian, 2015; Bertonha, 1998; Trento, 2013). 
Pasquino que utilizamos para as análises, dos quais alguns estão aqui apresentados.

\section{VIOLÊNCIA, DINHEIRO E EMPOLGAÇÃO}

Tudo impelia o Pasquino ao boxe: seu prestígio mundial, sua inserção no lazer através do cinema, das atividades clubísticas e dos espetáculos, além de sua presença em jornais concorrentes, como o Fanfulla. Com alguma reserva - e às vezes até com alguma antipatia - o Pasquino foi se relacionando cada vez mais com o universo pugilístico, sendo envolvido, mas também envolvendo-o; construindo representações entre as críticas, as zombarias e as excitações.

Ao longo de todo o século anterior, a prática do prizefighting sofrera processos de docilização até tornar-se boxe propriamente dito, fazendo concessões entre a excitação produzida e a necessidade de adaptação às novas sensibilidades das classes médias e burguesas urbanas, de modo a torná-lo palatável a um novo grupo, não apenas de praticantes, mas, sobretudo, de espectadores (Murphy e Sheard, 2006). Essa adequação da luta a novas sensibilidades "civilizadas" (Barrán, 2017) é o fenômeno que possibilita uma tal atividade adentrar os recantos das classes médias e burguesas, como são os teatros. Todavia, se podemos dizer que esse processo de abrandamento do pugilismo tornou-o mais aceitável entre certas frações da população, não podemos deixar de notar que, para um jornal burguês como o Pasquino, essa prática se encontrava na perigosa fronteira entre o aceitável e o repelível, entre o civilizado e o bárbaro, o excitante e o demasiado violento.

Numa matéria de 1928, há um diálogo fictício entre duas senhoras, no qual uma delas relata as angústias trazidas pelo fato de que seu filho decidira ser boxeador: o garoto socava tudo o que via pela frente, quebrando os móveis da casa; chamava o amigo para que se socassem mutuamente até sangrarem; contentava-se em estar com a cara quebrada, pois, quanto mais apanhasse, mais se habituaria a tanto; chegando à casa com sangue no nariz, queria ainda um soco na barriga - e, não fosse a mãe a lhe dar, seu amigo o fazia. A narrativa humorística é de uma mãe desesperada e cansada com um filho que ter-se-ia enveredado por um caminho incorreto, motivo de desgosto. A agressividade do menino em todos os momentos da vida é um vício atrelado à carreira boxística que desejava seguir, como se a agressividade do boxeador não fosse restrita a seu ofício, mas permeasse cada minuto de sua vida (GLI SPORTS..., 1928).

Comparando o esporte dos socos com o jogo da pelota, o jornal dizia que o boxe

[...] encerra métodos bárbaros e de discutibilíssimo gosto, absolutamente ausentes no nobre e cavalheiresco jogo basco (Sport, 1933, p. 11). ${ }^{5}$

${ }^{5}$ O jornal era todo (com raras exceções) publicado em idioma italiano. Todas as citações são traduções nossas.
De um lado, o nobre e cavalheiresco e, de outro, o barbarismo do pugilato.

Murros, portanto, e murros de todos os gêneros: socos na cara, no estômago, no coração, bofetadas, diretos, curvos, golpes de cima a baixo, tapas, sbirole, pancadas, gargamelle, leccamuffi, etc. etc. etc. (Cazzotti, 1925a, p. 16).

Já aqui temos uma espécie de contravocabulário: em lugar dos nomes técnicos que dignificam o esporte, os nomes chulos, um vocabulário mais vulgar, que tende a tragar o boxe de volta à agressividade baixa, desregulada, incivilizada.

A violência como característica inalienável desse esporte era de certo um alvo das críticas troceiras do jornal. Algo que se vê nos seus dizeres mais ou menos cômicos é uma ironização do título da noble art em decorrência de sua agressividade.

Realmente críamos que 'a arte nobre' pudesse ser a pintura, a escultura ou outra porcaria dessas. Em vez disso, arte nobre é o espancar com murros (Cazzotti, 1926c, p. 16).

A redução do boxe a "murros", como aponta o próprio nome da coluna que se inaugurou em 1925 (Cazzotti), contribuía para fazer pender a balança para um juízo desse esporte como mera violência física.

O humorismo do Pasquino era particularmente afiado e talhava o boxe com suas sátiras:

Havia muita gente [na noite de boxe no Frontão do Braz]; o que demonstra como em S. Paulo se tornam sempre mais intelectuais (Cazzotti, 1926b, p. 15).

Num texto que apresenta uma visita fictícia a Tex Richard, grande empresário da indústria do boxe, o entrevistado fala sobre uma nova forma de cortesia americana, que consistiria em tratar os companheiros com violência. Ele se diz o "apóstolo dos socos e da cortesia americana” (Parlando... 1927, p. 9).

Ademais, essa violência pugilística possuía um ar profano. Em 1926, uma matéria começa dizendo que poucas pessoas pagariam para ver uma arte religiosa, mas centenas e milhares vão ver um grande "esmurramento" (Cazzotti, 1926a) e, em 1928, o semanal anuncia assim a próxima partida, ironizando seu caráter profano ao usar um palavreado religioso:

Amanhã, à mercê de Deus, teremos a gentil ocasião de ver doze indivíduos empenhados no doce, no seráfico ofício de romper-se - a murros - caras e costelas (Cazzotti, 1928, p. 20, grifos nossos).

Em 1929, começa a crônica escrevendo que "Sábado passado fomos ao boxe. Pecado confessado é meio perdoado" (Cazzotti, 1929b, p. 11). Tal ar profano que envolvia práticas esportivas podia já ser encontrado desde meados do século anterior, quando os esportes ainda eram uma novidade pouco consolidada no 
universo recreativo dos brasileiros. O registro de um cronista de 1851, apreciado por Victor Melo (2015), questionava a presença das mulheres em divertimentos leigos como o turfe, enquanto os divertimentos mais "edificantes" da festividade religiosa estavam carentes do comparecimento feminino.

Paralelamente às representações do boxe como violência, havia também um certo desapreço do semanal em relação à indústria esportiva que se montava em torno da prática - "a bolsa", ele chamava, uma exigência gananciosa dos lutadores e dos promotores de eventos. Muitas das publicações do Pasquino vão considerar as reuniões pugilísticas como "'venda' de murros por 'atacado e a varejo...'" (Gazzotti, 1925, p. 14). Tex Richard, o "homem do dia", "com os socos, ganhou toneladas de dólares" (Parlando..., 1927, p. 9) - "Hoje é o século do boxe. Vejam... como me afortunei!" (ibid.). O dinheiro que corria pelas disputas estava sempre presente na imagem de boxe que o Pasquino produzia em suas páginas.

Os comentários sobre a "bolsa" eram mais do que meras constatações - eles expressavam uma valoração claramente negativa: "Essas, porém, são coisas que referem-se a eles e aqueles muitos idiotas que darão a eles seu dinheiro" (Cazzotti, 1928, p. 20). Em 1935, o Pasquino compara, colocando-se em posição de desvantagem, a sua atividade jornalística ao ramo do pugilato:

Mas ele recebe as bolsas; a nós as bolsas, se não se esvaziam, os inoportunos as rompem.

Portanto [o boxeador] Carnera leva as bolsas, o "Pasquino" leva a melancolia [...]

Um senhor do Rio ofereceu 100 contos a Uzedum para lutar com Carnera.

Não podia em vez disso esse magnífico senhor mandar pagar a assinatura do “Pasquino?" (Orticaria, 1935, p. 8)

Essa comparação não é fortuita. Existe um incômodo recorrente no Pasquino em relação ao enriquecimento através do esporte, possivelmente, como indicam as fontes, porque ele não passa pelas vias de ascensão social ortodoxas dos intelectuais que estavam à frente dos jornais - "E nas escolas os professores continuam a ensinar que o capital é fruto do trabalho e da poupança" (I Danari..., 1927, p. 8), ironizam os redatores. Uma dessas vias consagradas de mobilidade social, o semanal pontua, é a dos estudos e da diplomação:

O grande pugilista

faz o milionário:

entre ringue e diploma

há um grande abismo... (Inno..., 1930, p. 14)
Esse incômodo com uma atividade que enriquece sem passar pela aceitação de um modo de vida de uma classe média intelectual, uma atividade na qual o capital pugilístico incorporado se converte em capital econômico (Bourdieu, 1986) e para a qual não são necessários os mesmos êxitos educacionais que foram fundamentais para a constituição de um periódico frequentemente comandado por indivíduos de alta formação acadêmica, é pauta recorrente das charges ácidas do Pasquino. Em 1925, quando da aprovação pela Câmara Municipal de São Paulo para a prática do pugilismo, numa charge um senhor vestido em trajes distintos (terno e gravata, uma pasta sob o braço) interpela algumas crianças que se socam ao ar livre, ao que elas respondem: "Encontramos um trabalho! A Câmara Municipal permitiu o boxe e sabe-se que se ganha mais dinheiro distribuindo socos que fazendo-se médico ou fazendeiro!" (Pensando..., 1925, p.18). Novamente, em 1930, um desenho mostra o pai e o professor disputando um menino, o professor dizendo que ele deveria estudar, ao que o pai respondia: "não me faça rir: precisa aprender o 'boxe'!" (Cazzottare..., 1930, p. 7).

Seria contudo incorreto dizer do Pasquino que era apenas um ferrenho antagonista da prática pugilística, que tudo no boxe lhe parecia repulsivo, imoral e bárbaro. $\mathrm{Na}$ verdade, esse é um esporte que mora nas bordas do compreensível, do aceitável, do civilizado - e, no cambaleio sobre a fronteira, o jornal dava também seus passos no terreno da apreciação, de sorte que podemos encontrar em suas páginas as crônicas, a vibração, a preocupação com as questões relativas ao universo boxístico, o acompanhamento dos atletas favoritos e, principalmente, de seus patrícios.

Se a reserva marcou os primeiros anos de relação com o boxe, já no final de 1925 podia-se encontrar crônicas excitantes sobre as partidas, destacando os aspectos bem valorados da prática, como a astúcia, a inteligência, a força, a agilidade. O lutador Lage desferia golpes violentamente contra Bernhart, mas este, antecipando "inteligentemente" os socos, rindo-se do adversário, deixou Lage "Batido como um colchão velho" (Cazzotti, 1925c, p. 16). Em um conto de 1939, no qual uma mulher visita seu namorado boxeador em Paris, o Pasquino descreve as emoções que ela sentiu ao assistir uma luta pela primeira vez:

A noite do encontro foi uma grande noite. Arlette nunca havia assistido a uma partida de boxe e provou em poucos minutos mais emoções que em todo o resto da sua vida (Inglese, 1939, p. 90).

As expectativas para um espetáculo iam se formando, fomentadas nas letras que imprimia:

Amanhã se efetuará uma reunião de boxe na 'praça de touros'. Inacreditável. Joe Boykin vai jantar o pernambucano Victor Pereira (Insalata, 1926, p. 16).

Klausner enfrentaria em São Paulo o italiano Erminio Spalla, mas o Pasquino faz chacota - talvez fosse 
bom contra Lage, mas contra Spalla não teria chance (Dagliela..., 1926). Em 1927, dizia com entusiasmo: "Esta noite. Esta noite as coisas se complicam de um modo impressionante. No Teatro Colombo teremos um espetáculo nunca visto. [...] Até nós estamos em êxtase pela noite de quarta-feira" (Pugni..., 1927, p. 14).

A expectativa de excitação também poderia se frustrar, terminando com o Pasquino decepcionado, dizendo que "O boxe está perdendo terreno. Por quê? Porque de um mês pra cá vê-se sempre as mesmas caras. Não poderiam apresentar gente nova?" (SPUNTI..., 1929a, p. 12). No Madison Square Paulistano, as lutas poderiam desencantar o cronista que esperava sair de lá melhor comovido: "O melhor sonífero? As reuniões de boxe que se efetuam no sábado no ex Circo (ex por modo de dizer...) Queirolo. São garantidos oito dias de sono" (Spunti..., 1929b, pp. 13-4).

Esses são exemplos de que o boxe, apesar de causar reservas por sua violência e em alguma medida uma corrupção dos bons modos de ascensão social, também gerava vibração, emoção, expectativas.

\section{SOCOS CIENTÍFICOS}

O esporte é uma prática cultural em seus atos e em suas representações. Prática notadamente moderna, ${ }^{6}$ ele possui diversas faces, propósitos múltiplos e apropriações variadas. Por um lado, tem-se nele notado as características disciplinadoras, próprias de uma modernidade racional, que exige um controle rígido dos corpos em direção ao rendimento, e igualmente as suas ensinanças de competitividade e mérito próprias a uma modernidade capitalista; por outro, sempre cabe lembrar, ele é ainda fonte de divertimento, empolgação, sociabilidades e até mesmo evocador de crenças e ritos simbólicos. No caso do boxe no Pasquino, a cientificidade e a racionalidade aparecem como um registro de seus ares modernos, mas também como uma ironia frente à prática aparentemente bárbara do pugilismo.

O corpo moderno do esportista é um projeto, um tanto de representações que se pretende fazer valer por grupos que as produzem. ${ }^{7}$ A intelectualidade moderna, com estímulos da ciência, tensiona as representações

6 A modernidade da prática esportiva pode ser vista no trabalho de Dunning (2004) e na elaboração do tipo ideal de esporte moderno em Guttmann (2004). Essa característica do esporte torna-o um entre vários elementos de apelo das ideologias modernizantes, tais quais o Futurismo, como bem demonstrou Victor Melo (2007).

7 Os discursos que veiculam representações sobre o esporte ou sobre o corpo procuram prevalecer sobre outros e, por isso, a investigação sobre as representações "supõenas [não como absolutas, mas] como estando sempre colocadas num campo de concorrências e de competições cujos desafios se enunciam em termos de poder e de dominação" (Chartier, 1988, p. 17). sobre o corpo no sentido de vê-lo e fazer vê-lo como um objeto regido pelas leis científicas. Nesse sentido, o corpo é recorrentemente descrito em semelhança a uma máquina (Góis et al., 2015b). E, na fundação desses novos modos de entender o corpo, também se fazem necessárias sobre ele novas formas de educá-lo, de modo que as relações intuitivas com o corpo, consideradas perigosas, passam a ser racionalizadas, pedagogizadas ${ }^{8}$. No boxe, semelhantemente, a visão de uma descontrolada pancadaria entraria em confronto com uma ideia de luta científica, regida por saberes e valores modernos.

As conquistas, nesse paradigma, não se dariam por mero acaso, mas de acordo com um programa calculado de melhora do rendimento do novo corpo-máquina. Do espontâneo ao controlado; das qualidades essenciais às desenvolvidas. O corpo não é apenas um dado, torna-se um produto, uma natureza moldada, objeto externo ao sujeito, e tudo aquilo que vem antes da luta o constrói como um corpo lutador.

Para Alexandre Vaz (2003, p. 61),

O processo de racionalização do corpo, que encontra no esporte e no treinamento corporal que the corresponde uma de suas expressões privilegiadas, tem como desdobramento necessário a sua reificação, sua transformação em objeto manipulável, operável, medido, programado [...]

É com isso que surge algumas vezes no Pasquino a ideia dos "socos científicos" (Scazzottatture, 1925; Cazzotti, 1925b, 1929c; PUGNI..., 1925). Mas o boxe tem lá as suas peculiaridades e o pugilismo se encontra, para o Pasquino, nas fronteiras entre o racional e o bárbaro. A referência ao "esmurramento científico" (Cazzotti, 1926b) não é senão fruto dessas ambiguidades: ao mesmo tempo que propagandeia o discurso da cientificidade e da racionalidade de um esporte brutal, o faz sempre em um tom de chacota que o empurra, através da ironia, de volta ao âmbito de uma agressividade desregulada.

As ironias são esclarecedoras: "Esta noite teremos um espetáculo de 'boxe' que, para quem não sabe, é aquele 'nobre esporte' no qual dois homens devem atirar socos 'científicos', e romper reciprocamente o nariz, os dentes, as costelas e... o fio da vida!" (PUGNI..., 1925, p. 11). Como é, afinal, que um monte de murros dados, gerando ferimentos e podendo até derrubar um adversário para que ele nunca mais se levante, pode ser científico? Fazendo suas pilhérias, os redatores do jornal também tensionam as representações coletivas sobre o esporte, tendendo a tornar essa visão racionalizante do pugilismo mais escorregadia. Não sendo de uma militância anti-boxe, mas incapaz de se deixar insensível à sua aparente selvageria, o Pasquino tentava se equilibrar nessa mediana em que se permitia

8 As ginásticas positivas, como a do francês Georges Demeny, são aqui o exemplo notável. Ver Góis et al. (2015b). 
publicizar, narrar e prestigiar o boxe, mas também ironizar representações que lhe pareciam deslocadas, como o apelo à cientificidade de uma troca de socos.

\section{O NATO E O PRODUZIDO}

Uma das representações do cronista esportivo Gigi Polentina é a de que o lutador de boxe é algo que se fabrica (Polentina, 1931). Por mais que se repare em pesos, em altura, em alcance, ser um bom boxeador depende muito mais de seu treino e de sua experiência. É preciso amadurecer, conhecer os truques dos mestres, treinar as emoções, adquirir a astúcia. Por isso, dizia o autor, é que o gigante Carnera perdera o título de campeão mundial a Sharkey: Carnera ainda estava no começo da carreira e deveria passar pela aprendizagem, assim como outros grandes boxeadores que "apanhavam" no começo. Eis a trajetória do boxeador, quem trabalha sobre si mesmo na geração de um capital pugilístico necessário ao engrandecimento, à vitória. Seria sofrendo derrotas no início, coletando experiência, que Carnera, segundo Polentina, ganharia de Sharkey numa eventual revanche. Isso mostra que, no esporte, e especialmente no boxe, o cronista rejeita a ideia de sorte e diminui a importância das qualidades inatas: o sucesso de Carnera depende do trajeto difícil (e doloroso) que ele deve perseguir com paciência e insistência. O corpo do boxeador é um instrumento que precisa ser afiado.

Um texto de 1936, por outro lado, apresenta uma leitura que é, de certo modo, divergente à de Polentina (Lo Sport..., 1936, p.164-9). No lugar de uma competência aprimorada pela experiência - e, portanto, de aspecto humano, produzido -, ele descreve o pugilismo como uma continuidade de natureza. Em longas linhas, diferencia os esportes dos jogos: enquanto os últimos são uma invenção, para que "servissem ao homem como prazer de divertimento na fadiga física" - e incluem o futebol, o rúgbi, o hóquei, entre outros -, os primeiros "nasceram com o homem, porque eles são a expressão de um instinto". Os "fins" esportivos estariam na promoção da vida natural do homem e, em tempos recentes, teriam se desviado de seus princípios para que tais práticas se convertessem em espetáculos. Os esportes, nesse texto, seriam a caça, a pesca, o atletismo, o pugilato, a luta, a canoagem, o esqui, o nado e o... amor! Depois, o texto discorre sobre cada um deles, fazendo piada e contando sua história anedótica com humor.

O Pasquino propõe nesse texto que, embora as regras dos manuais ingleses tenham tornado o boxe docilizado em comparação com o "pugilato" 9 primitivo, o dito esporte - que "se pratica hoje apenas sobre os ringues" - também é colocado como um desenvolvimento moderno da violência humana. Se o pugilato antigo era,

9 Note-se que "pugilato" e "pugilismo" não são necessariamente a mesma coisa: o primeiro é sinônimo de luta ou briga, enquanto o seguindo refere-se à luta esportiva. Aqui, contudo, os dois termos aparecem especialmente aproximados. para o autor, mais brutal e desregrado, a luta moderna aparece como a sua continuidade, não como um jogo, inventado para curar a fadiga, mas como um "esporte" em sentido elaborado no texto - uma atividade instintiva posteriormente canalizada para o espetáculo.

\section{CONCLUSÕES}

O pugilismo foi, por algum tempo, citado apenas de maneira muito marginal no Pasquino, o qual, dando centralidade a outros esportes, nutria pela luta pouco interesse. Na década de 1920, contudo, a popularidade do boxe cresceu em todo o mundo ao tornar-se um negócio milionário, conquistando o público, penetrando os cinemas e os jornais concorrentes. Não mais podendo esquivar-se de uma presença tão marcante no cotidiano e na imprensa, o Pasquino passou, de início com ar de contrariado, a discorrer sobre o assunto, que foi ganhando cada vez mais espaço ao longo do tempo.

Em sua trajetória no jornal, o pugilismo foi representado de muitas maneiras, suscitando reações variadas e evocando valores diversos. Trata-se de uma prática que não tem nada de absoluto - e que talvez demonstre o quanto o esporte, afinal, pouco tem de características absolutas. Por um lado, tratava-se de socos científicos, mas, por outro, tinha também seu lado bárbaro, violento. Por um lado, era resultado de um esforço sobre si mesmo, do treinamento esportivo e, por outro, uma prática "natural" canalizada para o espetáculo. E, se ele aparecia muitas vezes como algo repulsivo, era em ainda mais ocasiões narrado como um jogo excitante, que comovia cronistas e leitores pelas emoções que proporcionava. Seus combates incríveis não perdiam sabor por serem também um modo pouco ortodoxo para fazer fortuna.

Nas páginas do Pasquino, o boxe era tudo isso. Como é frequente entre as práticas culturais, portanto, mobilizava representações múltiplas e até mesmo, às vezes, contraditórias.

\section{FINANCIAMENTO}

O presente trabalho foi realizado com apoio da Coordenação de Aperfeiçoamento de Pessoal de Nível Superior Brasil (CAPES) - Código de Financiamento 001P-3379/2017.

\section{CONFLITOS DE INTERESSE}

Os autores declaram não haver conflito de interesse.

\section{REFERÊNCIAS}

André JM. Quem não chora, não mama! Humor e representação cômica na história do design gráfico brasileiro - 1837-1931 [tese]. São Paulo: Universidade de São Paulo; 2010.

Araújo S, Cardoso, A. Italianos no Brasil ou a pátria recriada. In: De Boni L., organizador. A presença italiana no Brasil. Porto Alegre: Escola Superior de Tecnologia; 1987. p. 333-44. 
Barrán JP. Historia de la sensibilidad en el Uruguay. Montevideo: Banda Oriental; 2017.

Bertonha JF. Sob o signo do fascio: o fascismo, os imigrantes italianos e o Brasil, 1919-1945 [tese]. Campinas (SP): Universidade Estadual de Campinas; 1998. 424 p.

Bourdieu P. The forms of capital. In: Richardson J. Handbook of theory and research for the Sociology of Education. Westport: Greenwood; 1986. p. 241-58.

Caratti JM. Dentro e fora dos ringues: O processo de constituição do boxe moderno e sua difusão e recepção na América Latina (Séculos XVIII-XX) [tese]. Porto Alegre: Universidade Federal do Rio Grande do Sul; 2017. 552 p.

Chartier R. A história cultural: entre práticas e representações. Rio de Janeiro: Bertrand Brasil; 1988.

Dunning E. Sociologia do esporte e os processos civilizatórios. São Paulo: Annablume; 2004.

Góis $E$ Jr, Lódola S, Dyreson M. The rise of modern sport in Fin de Siècle São Paulo: reading elite and bourgeois sensibilities, the popular press, and the creation of cultural capital. Int J Hist Sport. 2015a; 2(14):1661-77. http://dx.doi. org/10.1080/09523367.2015.1120720.

Góis E Jr, Soares, CL, Terra VDS. Corpo-máquina: diálogos entre discursos científicos e a ginástica. Movimento 2015b;21(4):973-84.

Guttmann A. From ritual to record: The nature of modern sports. New York: Columbia university press; 2004.

Hall M. Imigrantes na cidade de São Paulo. In: Porta P. organizador. História da cidade de São Paulo. São Paulo: Paz e Terra; 2004. v. 3, p. 121-52.

Loudcher J-F, Day D. The international boxing Union (19131946): A European sports and/or political failure? Int J Hist Sport. 2013;30(17):2016-30. http://dx.doi.org/10.1080/0 9523367.2013.828038

Malatian T. Imprensa italiana em São Paulo e o fascismo: o Fanfulla (1921-1942). Historia 2015;34(1):195-215.

Melo VA. Esporte, futurismo e modernidade. História 2007;26(2):201-25.

Melo VA. Entre a elite e o povo: o sport no Rio de Janeiro do Século XIX (1851-1857). Tempo. 2015;21(37):208-29. http://dx.doi.org/10.1590/tem-1980-542x2015v213706.

Murphy P, Sheard K. Boxing blind: unplanned processes in the development of modern boxing. Sport Soc. 2006;9(4):54258. http://dx.doi.org/10.1080/17430430600768785.

Roberts R. Jack Dempsey: an American hero in the 1920's. J Pop Cult. 1974;8(2):411-26. http://dx.doi.org/10.1111/j.00223840.1974.00411.x

Roghatto G. Achiropita, fettuccine e vinho: sobre a italianidade e a colônia italiana de São Paulo. In: De Boni L. A presença italiana no Brasil vol. 2. Torino: Escola Superior de Tecnologia; Fondazione Gioivanni Agnelli; 1990. 414 p.

Trento A. Imprensa italiana no Brasil: séculos XIX e XX. São Carlos: EdUFSCar; 2013.

Truzzi O. Italianidade no interior paulista: percursos e descaminhos de uma identidade étnica (1880-1950). São Paulo: Unesp; 2016.

Vaz A. Corpo, educação e indústria cultural na sociedade contemporânea: notas para reflexão. Pro-Posições. 2003;14(2):61.

\section{FONTES}

CAZZOTTARE. Cazzottare necesse est, II Pasquino Coloniale, São Paulo, p. 7, 3 de maio de 1930.

CAZZOTTI. Cazzotti, II Pasquino Coloniale, São Paulo, p. 16, 26 de setembro de 1925a.

CAZZOTTI. Cazzotti, II Pasquino Coloniale, São Paulo, p. 15, 17 de outubro de 1925b.

CAZZOTTI. Cazzotti, II Pasquino Coloniale, São Paulo, p. 16, 26 de dezembro de 1925 c.

CAZZOTTI. Cazzotti, II Pasquino Coloniale, São Paulo, p. 15, 4 de setembro de 1926a.

CAZZOTTI. Cazzotti, II Pasquino Coloniale, São Paulo, p. 15, 11 de setembro de 1926b.

CAZZOTTI. Cazzotti, II Pasquino Coloniale, São Paulo, p. 16, 26 de junho de 1926c.

CAZZOTTI. Cazzotti, II Pasquino Coloniale, São Paulo, p. 20, 14 de abril de 1928.

CAZZOTTI. Cazzotti, II Pasquino Coloniale, São Paulo, p. 11, 27 de julho de 1929b

CAZZOTTI. Cazzotti, II Pasquino Coloniale, São Paulo, p. 14, 5 de outubro de 1929c.

CORREIO DA MANHÃ, Rio de Janeiro, p. 1, 2 de julho de 1921. CORREIO DA MANHÃ, Rio de Janeiro, p. 1, 3 de julho de 1921.

DAGLIELA. Dagliela a lui, II Pasquino Coloniale, São Paulo, p. 14, 13 de março de 1926.

GAZZOTTI. Gazzotti, II Pasquino Coloniale, São Paulo, p. 14-5, 21 de novembro de 1925.

GLI SPORTS. Gli sports preferiti, II Pasquino Coloniale, São Paulo, p. 21, 25 de agosto de 1928.

I DANARI. I danari dei bobos, II Pasquino Coloniale, São Paulo, p. 8, 1 de outubro de 1927.

INGLESE, Dott. Vicenzo. Volpi azzure, I/ Pasquino Coloniale, São Paulo, p. 90, 20 de dezembro de 1939.

INNO Inno al pugno, II Pasquino Coloniale, São Paulo, p. 14, 1 de março de 1930.

INSALATA. Insalata, /I Pasquino Coloniale, São Paulo, p. 16, 2 de janeiro de 1926.

LO SPORT. Lo sport non ha razza, Il Pasquino Coloniale, São Paulo, p. 164-9, 19 de dezembro de 1936.

ORTICARIA. Orticaria, // Pasquino Coloniale, São Paulo, p. 8, 26 de janeiro de 1935.

PARLANDO. Parlando con I'uomo del giorno, I/ Pasquino Coloniale, São Paulo, p. 9, 24 de setembro de 1927.

PENSANDO. Pensando all'avvenire, II Pasquino Coloniale, São Paulo, p. 18, 2 de maio de 1925.

POLENTINA, Gigi. Le lettere di Gigi Polentina, II Pasquino Coloniale, São Paulo, p. 8, 17 de outubro de 1931.

PUGNI. Pugni, pegni e pugni, Il Pasquino Coloniale, São Paulo, p. 14, 9 de abril de 1927.

PUGNI. Pugni, sinoni, Il Pasquino Coloniale, São Paulo, p. 11, 19 de setembro de 1925.

SCAZZOTTATTURE. Scazzottatture, II Pasquino Coloniale, São Paulo, p. 11, 25 de abril de 1925.

SPORT. Sport, II Pasquino Coloniale, São Paulo, p. 11, 6 de maio de 1933.

SPUNTI. Spunti a 90 l'ora, II Pasquino Coloniale, São Paulo, p. 12, 19 de outubro de 1929a.

SPUNTI. Spunti a 90 l'ora, II Pasquino Coloniale, São Paulo, p. 13-4, 26 de outubro de 1929b. 